\title{
PERISHABLE INVENTORY MODEL WITH FINITE RATE OF REPLENISHMENT HAVING GENERALIZED PARETO DECAY
}

\author{
Dr. Kousar Jaha Begum \\ Lecturer, \\ Government Degree College, \\ Visakhapatnam
Dr. Shaik Shamshuddin
Faculty,
GITAM University,
Visakhapatnam

\author{
Dr. K.Suryanarayana Rao \\ Assistant Professor of Statistics in the \\ Department of Science and Humanities in \\ Vignan's Institute of Engineering for Women, \\ Visakhapatnam, \\ Dr. Haniefuddin Shaik \\ Director, \\ CMT, \\ Visakhapatnam
}

Article DOI: https://doi.org/10.36713/epra3130

\begin{abstract}
In this paper an EPQ model for deteriorating items is developed and analyzed an inventory model for deteriorating items with the assumptions that the lifetime of the community is random and follows a Generalized Pareto distribution, having constant demand rate with shortages. The total cycle length in this model is divided into our non-over lapping intervals depending on the decrease of stock. Assuming that shortages are allowed and fully back backlogged, the differential equations governing the instantaneous state of inventory are developed and solved for $I(t)$. The loss due to deterioration, the total backlogged demand, the ordering quantity is also derived with suitable cost consideration. The total profit per unit time is developed and optimized with respect to the time at which production is to be started, time at which shortages occur, the time at which production is to be restated. The optimal ordering quantity, $Q$ is also obtained for given values of the parameters. $A$ numerical illustration is presented. This model also includes some of the earlier models as particular cases for specific values of the parameters.
\end{abstract}

KEYWORDS: Random Replenishment; Generalized Pareto Decay; Constant Demand; Shortages.

\section{INTRODUCTION}

Inventory modeling is a very important subject in logistics. Reducing cost while maintaining a quality is vital aspect for any organization. Having a solid inventory strategy could not only save company lots of money, but might be the difference between not being able to compete against the competition and having a well-known position in the market segment. However, relatively little consideration has been devoted to the inventory modeling of perishable goods. Dealing with perishable goods, particularly in the food industry, appears to be a significant problem.

However in many practical situations arising at places like oil and natural gas industries, chemical industries the life time of commodity is random and having variable rate of decay. Hence in this an inventory model for deteriorating items with finite rate of replenishment with the assumption that the lifetime of the commodity is random and follows a Generalized Pareto distribution with constant demand is developed and analyzed.

Using the differential equations the instantaneous state of inventory is obtained with suitable cost considerations. The total cost per unit time and profit rate functions are derived. The optimal ordering policy of the 
system is also obtained. The sensitivity of the model with respect to the parameters and costs are discussed with numerical values.

\section{REVIEW OF LITERATURE}

In the research paper titled "An EOQ model for deteriorating items with time varying demand and partial backlogging" classical economic order quantity model, it is often assumed that the shortages are either completely backlogged or completely lost. However, in some inventory systems, it is more reasonable to assume that the backlogging rate is dependent on the length of the waiting time for the next replenishment. The longer the waiting time is, the smaller the backlogging rate would be. In this paper, researchers focus on the effect of the backlogging rate on the economic order quantity decision. Numerical examples are presented to illustrate the model.

Moncer Hariga (1996) "Optimal EOQ Models for Deteriorating Items with Time-Varying Demand" in this paper, optimal inventory lot-sizing models are developed for deteriorating items with general continuous timevarying demand over a finite planning horizon and under three replenishment policies. The deterioration rate is assumed to be a constant fraction of the on-hand inventory. Shortages are permitted and are completely backordered. The proposed solution procedures are shown to generate global minimum replenishment schedules for both general increasing and decreasing demand patterns. An extensive empirical comparison using randomly generated linear and exponential demands revealed that the replenishment policy which starts with shortages in every cycle is the least cost policy and the replenishment policy which prohibits shortages in the last cycle exhibited the best service level effectiveness.

Ali Akbar Shaikh et al., (2019) "Price discount facility in an EOQ model for deteriorating items with stockdependent demand and partial backlogging" in their study observed economic order quantity (EOQ) models are cloistered by considering as constant not only the purchase cost (irrespective of the order size of the product) but also the carrying cost during the entire cycle period. However, the unit purchase cost has an antagonistic relationship with the order size, and the carrying cost has a commensurate relationship with the storage time-period of the product, that is, the higher the order size, the lower the unit purchase cost, and the longer the storage time-period, the greater carrying cost per unit. Also deterioration is another imperative issue in inventory analysis as it has a huge impact on profit or cost of the inventory system.

Liao, J., Huang, K., Chung, K. et al. (2020 Opined economic order quantity (EOQ) model has been used extensively over a century. This research paper is concerned with the finding of the optimal replenishment cycle time for the inventory issues where items received are partly with imperfect quality and involve deterioration after the inspection time. Also for financial safety, for the supplier, when the permissible delay in payments can promote their sales and reduce their on-hand stock level. In order to minimize the total relevant inventory cost, mathematical theorems have been developed to determine the existence and the uniqueness of the optimal solution. Numerical calculations and illustrations demonstrate the application and the performance of the proposed theories in this research paper.

Zhou, Y., Chen, C., Li, C., Zhong, Y.: "A synergic economic order quantity model with trade credit, shortages, imperfect quality and inspection errors" researchers developed a synergic economic order quantity (EOQ) model, in which trade credit, shortages, imperfect quality and inspection errors are taken into consideration simultaneously. We prove that the objective function of annual profit is strictly concave and show the closed-form optimal solution to the model. In special cases, some related EOQ models can be derived from our model, which they illustrate with numerical examples. Managerial implications are also proposed in this research.

Shin, M., Lee, H., Ryu, K., Cho, Y., \& Son, Y. J. (2019). “A two-phased perishable inventory model for production planning in a food industry" in their paper paper, a two-phased perishable inventory model for a food industry is proposed, where the inventory is perishable, but can be renewed by additional processing. The proposed model is applied and demonstrated with a kimchi processing facility in Korea. Two heuristic solution methods for generating its inventory management plan are also presented along with computational experiments.

Janssen, L., Sauer, J., Claus, T., \& Nehls, U. (2018). "Development and simulation analysis of a new perishable inventory model with a closing days constraint under non-stationary stochastic demand" developed a new age-based inventory model with a closing days constraint. This stochastic multi-item inventory model includes total stock capacity constraints, a positive lead time, a periodic inventory control, a target customer service level and mixed FIFO and LIFO issuing policies for perishable items with a fixed lifetime under a non-stationary random demand.

Saranya, N., \& Lawrence, A. S. (2019). "A stochastic inventory system with replacement of perishable items" researchers presents a continuous review perishable inventory system in which the perished items will be replaced by the supplier at a later time. Demands occur according to a Markov arrival process. The items in the 
inventory have exponential life times and these perished items are stored in a place, called pool for replacement. The $(\mathrm{s}, \mathrm{S})$ ordering policy is adopted. At the time of placing an order, the ordering quantity is adjusted with number of items in the pool. The lead time is assumed to have phase type distribution. The joint probability distribution of the inventory level and the number of pooled items is obtained in the steady state case using the matrix-geometric methods. Various system performance measures in the steady state are derived and the total expected cost rate is calculated under a prefixed cost structure.

Mandal, D., \& Venkataraman, S. V. (2019). “A dynamic programming model for perishable inventory management" develops a model which reduces such costs and hence increases the overall profit; researchers classify the entire lifetime of the products into two periods: in the first period a customer derives a higher utility from the product than from the second. In the traditional models discussed in literature, the net profit which is the difference between selling price and overall costs is maximised. Through this research, researchers propose a modification of this traditional model by varying the preferences of the product and hence its price over time.

Bhaula, B., Dash, J. K., \& Kumar, M. R. (2019) “An optimal inventory model for perishable items under successive price discounts with permissible delay in payments" derives an optimal ordering policy for noninstantaneously deteriorating items under successive price discounts with delay in payments. Here successive price discounts is a strategy to sell almost all the items before decomposition.

Waliv, R. H., \& Umap, H. P. (2019) "Stochastic inventory model with income and price dependent demand" in this paper a multi-item cost minimising stochastic inventory model is developed in stochastic environment. Demand is considered to be function of income level of consumer and price of commodity. Budget, income and price are assumed to be random and their randomness is expressed by normal distribution. Deterioration rate is modelled using Weibull distribution. Stochastic inventory model is converted into equivalent crisp inventory model by using stochastic nonlinear programming (SNLP) technique. Crisp problem is solved by fuzzy nonlinear programming (FNLP) technique and intuitionistic fuzzy optimisation (IFO) technique.

Saha, S., \& Sen, N. (2019) "An inventory model for deteriorating items with time and price dependent demand and shortages under the effect of inflation' this research paper presents an inventory model with selling price and time dependent demand, constant holding cost and time dependent deterioration. In this model, shortages are assumed to be partially backlogged. It is designed keeping in mind to optimise total inventory cost under the effect of inflation. For the solution of the model, an algorithm is proposed and illustrated with numerical values of system parameters. The optimal results are also presented graphically. Finally, sensitivity analysis is performed for different parametric values of system parameters.

\section{NOTATIONS AND ASSUMPTIONS}

\subsection{Notations}

Q: The ordering quantity in one cycle.

C: The cost per unit.

$\mathrm{h}$ : Inventory holding cost per unit per unit time.

$\pi$ : The shortage cost per unit per unit time.

$\mathrm{s}$ : Selling price of a unit.

$\mathrm{R}$ : Demand Rate $(<\mathrm{k})$

\subsection{Assumptions}

1. The demand rate is known

2. The lead time is zero

3. $\mathrm{T}$, the fixed duration of production cycle is known

4. $\mathrm{k}$, the production rate finite

5. Shortages are allowed and fully backlogged

6. Cost of placing an order is zero.

\section{INVENTORY MODEL WITH SHORTAGES}

Consider an inventory system in which the lifetime of commodity is random and follows a Generalized Pareto distribution having the probability density function 


$$
f(t)= \begin{cases}\frac{1}{a}\left(1-\frac{c t}{a}\right)^{\frac{1}{c}-1} & c \neq 0 \\ \frac{1}{a} e^{-\frac{t}{a}} & c=0\end{cases}
$$

The range of $\mathrm{t}$ is $0 \leq \mathrm{t}<\infty$ for $\mathrm{c} \leq 0$ and $0 \leq \mathrm{t} \leq \mathrm{a} / \mathrm{c}$ for $\mathrm{c}>0$

Where $\mathrm{c}$ is the shape parameter and $\mathrm{a}$ is the scale parameter.

Hence the instantaneous rate of deterioration $\mathrm{h}(\mathrm{t})$ is

$$
\mathrm{h}(\mathrm{t})=\frac{1 / a\left\{1-\frac{c t}{a}\right\}^{\frac{1}{c}-1}}{\left(1-\frac{c t}{a}\right)^{1 / c}}=\frac{1}{a-c t}
$$

The amount of stock is zero at time $\mathrm{t}=0$. Production starts at $\mathrm{t}=0$ and stops at $t=t_{1}$. The stock attains a level $S$ at $t=t_{1}$. During $\left(t_{1}, t_{2}\right)$ the inventory level gradually decreases mainly to meet up the demand and partly due to deterioration. By this process the stock reaches zero level at $t=t_{2}$. Now storages occur and accumulate to the level $P$ at $t=t_{3}$. Production starts again at $t=t_{3}$ and backlog is cleared at $t=T$. The cycle then repeats itself after time $\mathrm{T}$. The schematic diagram showing the inventory level over time is given in figure (2.1).

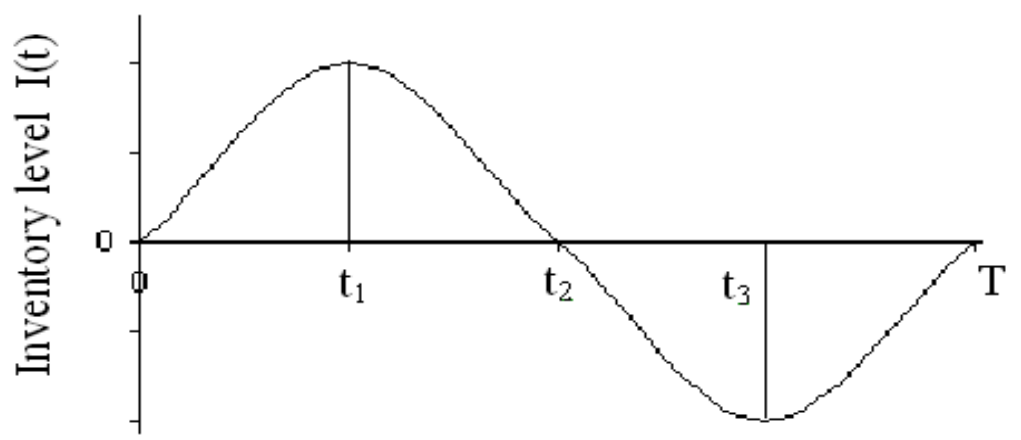

Time (t)

Let I ( $\mathrm{t}$ ) be the inventory level at time $\mathrm{t}(0 \leq \mathrm{t} \leq \mathrm{T})$. Then the differential equations describing the instantaneous state of $I(t)$ over the cycle of length $T$ are

$$
\begin{array}{lll}
\left.\frac{d}{d t} \mathrm{I}(\mathrm{t})+\mathrm{h} \mathrm{t}\right) \mathrm{I}(\mathrm{t})=\mathrm{k}-\mathrm{R} & \text { for } & 0 \leq \mathrm{t} \leq \mathrm{t}_{1} \\
\frac{d}{d t} \mathrm{I}(\mathrm{t})+\mathrm{h}(\mathrm{t}) \mathrm{I}(\mathrm{t})=-\mathrm{R} & \text { for } & \mathrm{t}_{1} \leq \mathrm{t} \leq \mathrm{t}_{2}
\end{array}
$$




$$
\begin{array}{lll}
\frac{d}{d t} \mathrm{I}(\mathrm{t})=-\mathrm{R}, & \text { for } & \mathrm{t}_{2} \leq \mathrm{t} \leq \mathrm{t}_{3} \\
\frac{d}{d t} \mathrm{I}(\mathrm{t})=\mathrm{k}-\mathrm{R}, & \text { for } & \mathrm{t}_{3} \leq \mathrm{t} \leq \mathrm{T}
\end{array}
$$

With initial conditions $\mathrm{I}(0)=0$; I $\left(\mathrm{t}_{1}\right)=\mathrm{S} ; \mathrm{I}\left(\mathrm{t}_{2}\right)=0$; I $\left(\mathrm{t}_{3}\right)=-\mathrm{P} ; \mathrm{I}(\mathrm{T})=0$.

Substituting $h(t)$ from equation (1) in equations (2) and (3) and solving the above differential equations, the on hand inventory at time $t$ can be obtained as

$$
\begin{array}{ll}
I(t)=\frac{(k-R)}{1-c}\left[(a-c t)-a^{1-1 / c}\left(a-c t_{1}\right)^{1 / c}\right], & 0 \leq \mathrm{t} \leq \mathrm{t}_{1} \\
I(t)=\frac{R}{1-c}\left[(a-c t)^{1 / c}\left(a-c t_{2}\right)^{-1 / c}-(a-c t)\right], & \mathrm{t}_{1} \leq \mathrm{t} \leq \mathrm{t}_{2} \\
I(\mathrm{t})=-\mathrm{R}\left(\mathrm{t}-\mathrm{t}_{2}\right), & \mathrm{t}_{2} \leq \mathrm{t} \leq \mathrm{t}_{3} \\
I(\mathrm{t})=-(\mathrm{k}-\mathrm{R})(\mathrm{T}-\mathrm{t}), & \mathrm{t}_{3} \leq \mathrm{t} \leq \mathrm{T}
\end{array}
$$

The stock loss due to deterioration in the interval $(\mathrm{O}, \mathrm{T})$ is

$$
\mathrm{L}(\mathrm{T})=\mathrm{kt}_{1}-\mathrm{R}_{2}
$$

The backlogged demand at time $t$ in the interval $\left(\mathrm{t}_{2}, \mathrm{t}_{3}\right)$

$$
B(t)=R\left(t-t_{2}\right) \quad t_{2} \leq t \leq t_{3}
$$

The ordering quantity $\mathrm{Q}$ in a cycle of length $\mathrm{T}$ is obtained as

$$
\mathrm{Q}=\mathrm{k}\left(\mathrm{T}+\mathrm{t}_{1}-\mathrm{t}_{3}\right)
$$

Let $\mathrm{K}\left(\mathrm{t}_{1}, \mathrm{t}_{2}, \mathrm{t}_{3}, \mathrm{~T}\right)$ be the total cost per unit time. Since the total cost is the sum of the cost of the units, the inventory holding cost and shortage cost, $\mathrm{K}\left(\mathrm{t}_{1}, \mathrm{t}_{2}, \mathrm{t}_{3}, \mathrm{~T}\right)$ is obtained as

$$
\mathrm{K}\left(\mathrm{t}_{1}, \mathrm{t}_{2}, \mathrm{t}_{3}, \mathrm{~T}\right)=\frac{C Q}{T}+\frac{h}{T}\left[\int_{0}^{t_{1}} I(t) d t+\int_{t_{1}}^{t_{2}} I(t) d t\right]+\frac{\pi}{T}\left\{\int_{t_{2}}^{t_{3}} I(t) d t+\int_{t_{3}}^{T} I(t) d t\right\}
$$

Substituting, the equations (2.2.6), (2.2.7), (2.2.8), (2.2.9) and (2.2.12) in the equation (2.2.13), the total cost per unit time is obtained as

$$
\begin{aligned}
& \mathrm{K}\left(\mathrm{t}_{1}, \mathrm{t}_{2}, \mathrm{t}_{3}, \mathrm{~T}\right)=\frac{C k}{T}\left(T+t_{1}-t_{3}\right) \\
& +\frac{h}{T}\left\{\int_{0}^{t_{1}} \frac{(k-R)}{1-c}\left[(a-c t)-a^{1-1 / c}(a-c t)^{1 / c}\right] d t+\int_{t_{1}}^{t_{2}} \frac{R}{1-c}\left[(a-c t)^{1 / c}\left(a-c t_{2}\right)^{1-1 / c}-(a-c t)\right] d t\right\}
\end{aligned}
$$




$$
+\frac{\pi}{\mathrm{T}}\left\{\int_{t_{2}}^{t_{3}} R\left(t-t_{2}\right) \cdot d t+\int_{t_{3}}^{T}(k-R)(T-t) d t\right\}
$$

On Integrating, we obtain $\mathrm{K}\left(\mathrm{t}_{1}, \mathrm{t}_{2}, \mathrm{t}_{3}, \mathrm{~T}\right)$ as

$$
\begin{aligned}
& \mathrm{K}\left(\mathrm{t}_{1}, \mathrm{t}_{2}, \mathrm{t}_{3}, \mathrm{~T}\right)=\frac{C k}{T}\left(T+t_{1}-t_{3}\right) \\
&+ \frac{h}{T(1-c)}\left\{(k-R)\left[a t_{1}-\frac{c t_{1}}{2}+a^{1-1 / c} \frac{\left(a-c t_{1}\right)^{1 / c+1}}{1+c}-\frac{a^{2}}{1+c}\right]\right. \\
&+R\left[\frac{c}{2}\left(t_{2}^{2}-t_{1}^{2}\right)-a\left(t_{2}-t_{1}\right)\right] \\
&\left.-\frac{1}{1+c}\left[\left(a-c t_{2}\right)^{2}-\left(a-c t_{1}\right)^{1+1 / c}\left(a-c t_{2}\right)^{1-1 / c}\right]\right\} \\
&+\frac{\pi}{2 \mathrm{~T}}\left\{R\left(t_{3}-t_{2}\right)^{2}+(k-R)\left(T-t_{3}\right)^{2}\right\}
\end{aligned}
$$

The profit rate function $P\left(t_{1}, t_{2}, t_{3}, T, s\right)$ can be written as

$$
\mathrm{P}\left(\mathrm{t}_{1}, \mathrm{t}_{2}, \mathrm{t}_{3}, \mathrm{~T}, \mathrm{~s}\right)=\frac{s R t_{3}}{T}-K\left(t_{1}, t_{2}, t_{3}, T\right)
$$

Substituting the equation (2.2.15) in equation (2.2.16) the profit rate function of the model can be obtained as

$\mathrm{P}\left(\mathrm{t}_{1}, \mathrm{t}_{2}, \mathrm{t}_{3}, \mathrm{~T}, \mathrm{~s}\right)=\frac{s R t_{3}}{T}-\frac{C k}{T}\left(T+t_{1}-t_{3}\right)$

$$
\begin{aligned}
& -\frac{h}{T(1-c)}\left\{(k-R)\left[a t_{1}-\frac{c t_{1}^{2}}{2}+\frac{a^{1-1 / c}\left(a-c t_{1}\right)^{1+1 / c}}{1+c}-\frac{a^{2}}{1+c}\right]\right. \\
& \left.+R\left[\left[\frac{c}{2}\left(t_{2}^{2}-t_{1}^{2}\right)-a\left(t_{2}-t_{1}\right)\right]-\frac{1}{1+c}\left[\left(a-c t_{2}\right)^{2}-\left(a-c t_{1}\right)^{1+1 / c}\left(a-c t_{2}\right)^{1-1 / c}\right]\right]\right\} \\
& -\frac{\pi}{2 T}\left\{R\left(t_{3}-t_{2}\right)^{2}+(k-R)\left(T-t_{3}\right)^{2}\right\}
\end{aligned}
$$

\section{OPTIMAL ORDERING POLICY OF THE MODEL}

In this section the optimal ordering policy of the inventory system developed in section (2) is obtained. To find the optimal values of $t_{1}, t_{2}, t_{3}$, we equate the first order partial derivatives of $P\left(t_{1}, t_{2}, t_{3}, T, s\right)$ with respect to $t_{1}, t_{2}$ and $t_{3}$ to zero respectively.

By differentiating $P\left(t_{1}, t_{2}, t_{3}, s\right)$ w.r.t to $t_{1}$ and equating to zero. we get, 


$$
C k+\frac{h}{1-c}\left\{(k-R)\left[\left(a-c t_{1}\right)-a^{1-1 / c}\left(a-c t_{1}\right)^{1 / c}\right]+R\left[\left(a-c t_{1}\right)-\left(a-c t_{2}\right)^{1-1 / c}\left(a-c t_{1}\right)^{1 / c}\right]\right\}=0
$$

By differentiating $P\left(t_{1}, t_{2}, t_{3}, T, s\right)$ with respect to $t_{2}$ and equating to zero, we get

$$
\frac{h}{1+c}\left\{\left(c t_{2}-a\right)+\left(a-c t_{1}\right)^{1+1 / c}(a-c t)^{-1 / c}\right\}-\pi\left\{t_{3}-t_{2}\right\}=0
$$

By differentiating $P\left(t_{1}, t_{2}, t_{3}, T, s\right)$ with respect to $t_{3}$ and equating to zero, we get

$$
s R+C k+\pi\left[k\left(T-t_{3}\right)-R\left(T-t_{2}\right)\right]=0
$$

By solving the equations (18), (19) and (20) simultaneously, the optimal time at which the production is to be stopped $t_{1}{ }^{*}$ of $t_{1}$, the time at which shortages will start $t_{2}{ }^{*}$ of $t_{2}$, and the optimal time at which the production should be restarted, $\mathrm{t}_{3}{ }^{*}$ of $\mathrm{t}_{3}$ can be obtained.

\section{NUMERICAL ILLUSTRATIONS}

As a numerical illustration the optimal values $\mathrm{t}_{1}{ }^{*}, \mathrm{t}_{2}{ }^{*}, \mathrm{t}_{3}{ }^{*}, \mathrm{P}$ and $\mathrm{Q}$ are obtained for given values of the parameters .

TABLE 1

Optimal values of production time, time at which shortages occur, time at which production is restarted, profit and optimal ordering quantity (when $\mathrm{c}$ is positive)

\begin{tabular}{|c|c|c|c|c|c|c|c|c|c|c|c|c|c|}
\hline $\mathbf{a}$ & $\mathbf{c}$ & $\mathbf{k}$ & $\mathbf{h}$ & $\mathbf{R}$ & $\boldsymbol{\pi}$ & $\mathbf{C}$ & $\mathbf{s}$ & $\mathbf{T}$ & $\mathbf{t}_{\mathbf{1}}{ }^{*}$ & $\mathbf{t}_{2}{ }^{*}$ & $\mathbf{t}{ }^{*}$ & $\mathbf{P}$ & $\mathbf{Q}^{*}$ \\
\hline 200 & 0.4 & 100 & 0.25 & 60 & 0.1 & 5 & 15 & 500 & 150.82946 & 223.72147 & 474.2328 & 27.512 & 17659 \\
201 & & & & & & & & & 150.36042 & 223.4474 & 474.068 & 27.4188 & 17629 \\
202 & & & & & & & & & 149.90228 & 223.18107 & 473.908 & 27.3283 & 17599 \\
203 & & & & & & & & & 149.4546 & 222.922 & 473.753 & 27.240 & 17570 \\
\hline 200 & 0.41 & 100 & 0.25 & 60 & 0.1 & 5 & 15 & 500 & 151.189 & 223.76192 & 474.2571 & 27.403 & 17693 \\
& 0.42 & & & & & & & & 151.555 & 223.800 & 474.28 & 27.29 & 17727 \\
& 0.43 & & & & & & & & 151.928 & 223.83 & 474.30 & 27.17 & 17762 \\
\hline 200 & 0.4 & 101 & 0.25 & 60 & 0.1 & 5 & 15 & 500 & 146.123 & 219.78 & 472.64 & 21.492 & 17521 \\
& & 102 & & & & & & & 141.7423 & 216.13 & 471.25 & 15.71 & 17389 \\
& & 103 & & & & & & & 137.64818 & 212.731 & 470.037 & 10.152 & 17263 \\
\hline 200 & 0.4 & 100 & 0.26 & 60 & 0.1 & 5 & 15 & & 144.86442 & 216.625 & 469.975 & 17.007 & 17488 \\
& & & 0.27 & & & & & & 139.377 & 209.999 & 465.99 & 7.084 & 17337 \\
& & & 0.275 & & & & & & 136.794 & 206.84 & 464.107 & 2.326 & 17268 \\
\hline 200 & 0.4 & 100 & 0.25 & 61 & 0.1 & 5 & 15 & 500 & 159.374 & 230.37 & 477.35 & 38.58 & 18201 \\
& & & & 62 & & & & & 168.85903 & 238.95 & 481.149 & 50.458 & 18770 \\
& & & & 63 & & & & & 179.5389 & 248.059 & 485.77 & 63.226 & 19376 \\
\hline 200 & 0.4 & 100 & 0.25 & 60 & 0.09 & 5 & 15 & 500 & 139.702 & 211.77 & 482.62 & 68.40 & 15708 \\
& & & & & 0.08 & & & & 128.5645 & 199.529 & 494.717 & 116.42 & 13384 \\
& & & & & 0.07 & & & & 117.397 & 186.94 & 512.166 & 174.00 & 10523 \\
\hline 200 & 0.4 & 100 & 0.25 & 60 & 0.1 & 5.1 & & & 149.908 & 223.11 & 474.86 & 23.99 & 17504 \\
& & & & & & 5.5 & & & 146.289 & 220.74 & 477.44 & 10.24 & 16884 \\
& & & & & & 6.0 & & & 144.51 & 219.58 & 478.75 & 3.548 & 16576 \\
\hline 200 & 0.4 & 100 & 0.25 & 60 & 0.1 & 5 & 15.5 & & 153.88 & 226.95 & 479.17 & 56.11 & 17471 \\
& & & & & & & 16 & & 157.018 & 230.24 & 484.14 & 85.13 & 17287 \\
& & & & & & & 16.5 & & 160.2314 & 233.601 & 489.16 & 114.21 & 17107 \\
\hline
\end{tabular}


Table 2

Optimal values of production time, time at which shortages occur, time at which production is restarted, profit and optimal ordering quantity (when $\mathrm{c}$ is negative)

\begin{tabular}{|c|c|c|c|c|c|c|c|c|c|c|c|c|c|}
\hline $\mathbf{a}$ & c & K & H & $\mathbf{R}$ & $\pi$ & C & $\mathbf{s}$ & $T$ & $\mathbf{t}_{1}{ }^{*}$ & $\mathbf{t}_{2}{ }^{*}$ & $\mathbf{t}_{3}{ }^{*}$ & $\mathbf{P}$ & $\mathbf{Q}^{*}$ \\
\hline $\begin{array}{l}200 \\
201 \\
202 \\
203\end{array}$ & -8 & 100 & 0.25 & 60 & 0.1 & 5 & 15 & 500 & $\begin{array}{c}112.41591 \\
112.4037 \\
112.39152 \\
112.37939\end{array}$ & $\begin{array}{c}211.45826 \\
211.44916 \\
211.4401 \\
211.4310\end{array}$ & $\begin{array}{c}466.87496 \\
466.8695 \\
466.86406 \\
466.858\end{array}$ & $\begin{array}{l}29.94 \\
29.92 \\
29.91 \\
29.90\end{array}$ & $\begin{array}{l}14554 \\
14553 \\
14552 \\
14551\end{array}$ \\
\hline 200 & $\begin{array}{l}-6 \\
-5 \\
-4\end{array}$ & 100 & 0.25 & 60 & 0.1 & 5 & 15 & 500 & $\begin{array}{c}114.19147 \\
115.43 \\
117.057\end{array}$ & $\begin{array}{c}212.301 \\
212.8736 \\
213.60\end{array}$ & $\begin{array}{c}467.381 \\
467.724 \\
468.1616\end{array}$ & $\begin{array}{c}30.370 \\
30.62 \\
30.89\end{array}$ & $\begin{array}{l}14681 \\
14770 \\
14889\end{array}$ \\
\hline 200 & -8 & $\begin{array}{l}101 \\
102 \\
103\end{array}$ & 0.25 & 60 & 0.1 & 5 & 15 & 500 & $\begin{array}{l}110.1067 \\
107.8902 \\
105.7605\end{array}$ & $\begin{array}{l}209.696 \\
208.016 \\
206.412\end{array}$ & $\begin{array}{c}466.6514 \\
466.4802 \\
466.356\end{array}$ & $\begin{array}{l}25.48 \\
21.15 \\
16.95\end{array}$ & $\begin{array}{l}14489 \\
14423 \\
14358\end{array}$ \\
\hline 200 & -8 & 100 & $\begin{array}{l}0.26 \\
0.27 \\
0.28 \\
\end{array}$ & 60 & 0.1 & 5 & 15 & 500 & $\begin{array}{l}109.478 \\
106.683 \\
104.021 \\
\end{array}$ & $\begin{array}{l}205.602 \\
200.059 \\
194.805 \\
\end{array}$ & $\begin{array}{c}463.361 \\
460.035 \\
456.88 \\
\end{array}$ & $\begin{array}{c}19.47 \\
9.5 \\
0.2 \\
\end{array}$ & $\begin{array}{l}14611 \\
14664 \\
14713 \\
\end{array}$ \\
\hline 200 & -8 & 100 & 0.25 & $\begin{array}{l}61 \\
62 \\
63\end{array}$ & 0.1 & 5 & 15 & 500 & $\begin{array}{c}116.41972 \\
120.5798 \\
124.908\end{array}$ & $\begin{array}{c}214.539 \\
217.77 \\
221.180\end{array}$ & $\begin{array}{c}467.369 \\
468.02 \\
468.843\end{array}$ & $\begin{array}{l}38.18 \\
46.85 \\
55.94\end{array}$ & $\begin{array}{l}14905 \\
15255 \\
15606\end{array}$ \\
\hline 200 & -8 & 100 & 0.25 & 60 & $\begin{array}{l}0.09 \\
0.08 \\
0.07\end{array}$ & 5 & 15 & 500 & $\begin{array}{c}106.852 \\
100.9418 \\
94.653\end{array}$ & $\begin{array}{c}202.634 \\
193.25 \\
183.27\end{array}$ & $\begin{array}{c}477.13 \\
490.954 \\
509.965\end{array}$ & $\begin{array}{l}72.31 \\
121.4 \\
179.7\end{array}$ & $\begin{array}{c}12971 \\
10998 \\
8468\end{array}$ \\
\hline 200 & -8 & 100 & 0.25 & 60 & 0.1 & $\begin{array}{c}5.1 \\
5.5 \\
6\end{array}$ & 15 & 500 & $\begin{array}{c}111.99 \\
110.33 \\
108.258\end{array}$ & $\begin{array}{c}211.42 \\
211.269 \\
211.08\end{array}$ & $\begin{array}{c}467.85 \\
471.761 \\
476.648\end{array}$ & $\begin{array}{c}27.04 \\
15.73 \\
2.22\end{array}$ & $\begin{array}{l}14414 \\
13857 \\
13160\end{array}$ \\
\hline 200 & -8 & 100 & 0.25 & 60 & 0.1 & 5 & $\begin{array}{l}15.5 \\
16.0 \\
16.5\end{array}$ & 500 & $\begin{array}{c}113.819 \\
115.22 \\
116.62\end{array}$ & $\begin{array}{c}213.68 \\
215.910 \\
218.13\end{array}$ & $\begin{array}{c}471.210 \\
475.54 \\
479.88\end{array}$ & $\begin{array}{l}58.08 \\
86.48 \\
115.1\end{array}$ & $\begin{array}{l}14260 \\
13967 \\
13674\end{array}$ \\
\hline
\end{tabular}

From Tables $1 \& 2$ we observe that when the scale parameter, a is increasing then the optimal time at which production is to be stopped, $\mathrm{t}_{1} *$ of $\mathrm{t}_{1}$, the time at which shortages will start, $\mathrm{t}_{2} *$ of $\mathrm{t}_{2}$, the optimal time at which the production should be restarted, $\mathrm{t}_{3} *$ of $\mathrm{t}_{3}$, the profit per unit time, $\mathrm{P}$ and the optimal ordering quantity, $\mathrm{Q}^{*}$ of $\mathrm{Q}$ are decreasing for a given Cycle length $\mathrm{T}$, when other parameters and costs are fixed.

When the shape parameter, $\mathrm{c}$ is increasing positively or negatively then the optimal time at which the production is to be stopped, $\mathrm{t}_{1} *$ of $\mathrm{t}_{1}$, the optimal ordering quantity $\mathrm{Q}^{*}$ of $\mathrm{Q}$, the time at shortages will start, $\mathrm{t}_{2} *$ of $\mathrm{t}_{2}$, the optimal time at which the production should be restarted, $\mathrm{t}_{3} *$ of $\mathrm{t}_{3}$ are increasing the profit per unit time, $\mathrm{P}$ is decreasing for a given cycle length $\mathrm{T}$, when other parameters and costs are fixed.

When production rate $\mathrm{k}$ is increasing, then the optimal time at which production is to be stopped, $\mathrm{t}_{1} *$ of $\mathrm{t}_{1}$, the time at which shortages will start, $\mathrm{t}_{2} *$ of $\mathrm{t}_{2}$, the optimal time at which the production should be restarted, $\mathrm{t}_{3} *$ of $\mathrm{t}_{3}$, the profit per unit time, $\mathrm{P}$ and the optimal ordering quantity, $\mathrm{Q}^{*}$ of $\mathrm{Q}$ are decreasing for a given Cycle length $\mathrm{T}$, when other parameters and costs are fixed.

When holding cost, $h$ is increasing, then the optimal time at which production is to be stopped, $t_{1} *$ of $t_{1}$, the time at which shortages will start, $t_{2} *$ of $t_{2}$, the optimal time at which production should be started, $t_{3} *$ of $t_{3}$, the profit per unit time, $\mathrm{P}$, are decreasing for a given cycle length $\mathrm{T}$, but the optimal ordering quantity $\mathrm{Q}^{*}$ of $\mathrm{Q}$ is decreasing when $\mathrm{c}>0$ and the optimal ordering quantity $\mathrm{Q}^{*}$ of $\mathrm{Q}$ is increasing when $\mathrm{c}<0$, when other parameters and costs are fixed.

When the demand rate, $\mathrm{R}$ is increasing then the optimal time at which production is to be stopped, $\mathrm{t}_{1} *$ of $\mathrm{t}_{1}$, the time at which shortages will start, $\mathrm{t}_{2} *$ of $\mathrm{t}_{2}$, the optimal time at which production should be started, $\mathrm{t}_{3} *$ of $\mathrm{t}_{3}$, the profit per unit time, $\mathrm{P}$, the optimal ordering quantity $\mathrm{Q}^{*}$ of $\mathrm{Q}$ are increasing, when other parameters and costs are fixed.

When shortage cost, $\pi$ is increasing then the optimal time at which production should be stopped, $t_{1} *$ of $t_{1}$, the time at which shortages will start, $\mathrm{t}_{2} *$ of $\mathrm{t}_{2}$, the optimal ordering quantity, $\mathrm{Q} *$ of $\mathrm{Q}$ are increasing and the time at which the production is to be restarted $t_{3} *$ of $t_{3}$ and profit per unit time, $\mathrm{P}$ are decreasing for a given cycle length, $\mathrm{T}$, when other parameters and costs are fixed.

When unit cost, $C$ is increasing then the optimal time at which production should be stopped $t_{1} *$ of $t_{1}$, the time at which shortages will start, $\mathrm{t}_{2} *$ of $\mathrm{t}_{2}$, profit per unit time, $\mathrm{P}$, the optimal ordering quantity $\mathrm{Q}^{*}$ of $\mathrm{Q}$ are 
decreasing and the time at which production should be restarted, $\mathrm{t}_{3} *$ of $\mathrm{t}_{3}$ is increasing, for a given cycle length, $\mathrm{T}$, when other parameters and costs are fixed.

When unit selling price, $\mathrm{s}$ is increasing then the optimal time at which production should be stopped, $\mathrm{t}_{1} *$ of $t_{1}$, the time at which shortages will start, $t_{2} *$ of $t_{2}$, the optimal time at which the production should be restarted, $t_{3}^{*}$ of $\mathrm{t}_{3}$, the profit per unit time, $\mathrm{P}$ are increasing and the optimal ordering quantity, $\mathrm{Q}^{*}$ of $\mathrm{Q}$ is decreasing for a given cycle length, $\mathrm{T}$, when other parameters and costs are fixed.

\section{INVENTORY MODEL WITHOUT SHORTAGES}

In this section the model without shortages is developed and analyzed. For developing model under study, we take $\pi \rightarrow \infty$ and $t_{2} \rightarrow T$. The differential equations governing the instantaneous state of inventory level of the system at time $t$ of the model are

$$
\begin{array}{ll}
\frac{d}{d t} I(t)+h(t) I(t)=k-R & 0 \leq \mathrm{t} \leq \mathrm{t}_{1} \\
\frac{d}{d t} I(t)+h(t) I(t)=-R, & 0 \leq \mathrm{t} \leq \mathrm{T}
\end{array}
$$

with initial conditions $\mathrm{I}(0)=0, \mathrm{I}(\mathrm{T})=0$

The on hand inventory level at time $t$ is

$$
\begin{aligned}
& I(t)=\frac{k-R}{1-c}\left[(a-c t)-a^{1-1 / c}(a-c t)^{1 / c}\right] \\
& I(t)=\frac{R}{1-c}\left[(a-c t)^{1 / c}(a-c T)^{1-1 / c}-(a-c t)\right]
\end{aligned}
$$

The stock loss due to deterioration in the interval $(0, \mathrm{~T})$ is

$$
L(T)=k t_{1}-R T
$$

The ordering quantity in a cycle of length $\mathrm{T}$ is obtained as

$$
\mathrm{Q}=\mathrm{kt}_{1}
$$

The total cost per unit time $\mathrm{K}\left(\mathrm{t}_{1}, \mathrm{~T}\right)$ is

$$
\begin{aligned}
& K\left(t_{1}, T\right)=\frac{C k t_{1}}{T}+\frac{h}{T(1-c)}\left\{(k-R)\left[a t_{1}-\frac{c t_{1}^{2}}{2}+\frac{a^{1-1 / c}\left(a-c t_{1}\right)^{1+1 / c}}{1+c}-\frac{a^{2}}{1+c}\right]\right. \\
&\left.+R\left[\left[\frac{c}{2}\left(T^{2}-t_{1}^{2}\right)-a\left(T-t_{1}\right)\right]-\frac{1}{1+c}\left[(a-c T)^{2}-\left(a-c t_{1}\right)^{1+1 / c}(a-c T)^{1-1 / c}\right]\right]\right\}
\end{aligned}
$$

The profit rate function $P\left(t_{1}, T_{s}\right)$ is 


$$
\begin{aligned}
P\left(t_{1}, T, s\right)=s R-\frac{C k t_{1}}{T} & -\frac{h}{T(1-c)}\left\{(k-R)\left[a t_{1}-\frac{c t_{1}^{2}}{2}+\frac{a^{1-1 / c}\left(a-c t_{1}\right)^{1+1 / c}}{1+c}-\frac{a^{2}}{1+c}\right]\right. \\
+R & {\left.\left[\left[\frac{c}{2}\left(T^{2}-t_{1}^{2}\right)-a\left(T-t_{1}\right)\right]-\frac{1}{1+c}\left[(a-c T)^{2}-\left(a-c t_{1}\right)^{1+1 / c}(a-c T)^{1-1 / c}\right]\right]\right\} }
\end{aligned}
$$

To find the optimal value of $t_{1}$, we equate the first order derivative of $P\left(t_{1}, T, s\right)$ with respect to $t_{1}$, to zero.

By differentiating $\mathrm{P}\left(\mathrm{t}_{1}, \mathrm{~T}, \mathrm{~s}\right)$ with respect to $\mathrm{t}_{1}$ and equating to zero, we get $C k+\frac{h}{1-c}\left\{(k-R)\left[a-c t_{1}-a^{1-1 / c}\left(a-c t_{1}\right)^{1 / c}\right]+R\left[\left(a-c t_{1}\right)-(a-c T)^{1-1 / c}\left(a-c t_{1}\right)^{1 / c}\right]\right\}=0$

By solving (29) the optimal time at which the production is to be stopped $t^{*}{ }_{1}$ of $t_{1}$, profit for unit time and optimal ordering quantity are computed for different values of the parameters and costs.

\section{NUMERICAL ILLUSTRATION}

As a numerical illustrations the optimal values of $t_{1} * Q^{*}$ are obtained for given values of parameters and costs using MATHCAD are computed and given in Table 3 for $\mathrm{c}>0$, and in Table 4 for $\mathrm{c}<0$.

Table 3

Optimal values of production time, profit and ordering quantity (when $\mathrm{c}$ is positive)

\begin{tabular}{|c|c|c|c|c|c|c|c|c|c|c|}
\hline $\mathbf{a}$ & $\mathbf{c}$ & $\mathbf{k}$ & $\mathbf{h}$ & $\mathbf{R}$ & $\mathbf{C}$ & $\mathbf{s}$ & $\mathbf{T}$ & $\mathbf{t}_{\mathbf{1}}{ }^{*}$ & $\mathbf{P}$ & $\mathbf{Q}^{*}$ \\
\hline 26 & 0.4 & 60 & 0.5 & 50 & 5 & 20 & 55 & 47.94 & 673.235 & 2876 \\
27 & & & & & & & & 47.28 & 673.14 & 2837 \\
28 & & & & & & & & 46.71 & 672.931 & 2803 \\
\hline 25 & 0.42 & 60 & 0.5 & 50 & 5 & 20 & 55 & 48.781 & 671.394 & 2987 \\
& 0.43 & & & & & & & 50.478 & 670.037 & 3029 \\
& 0.44 & & & & & & & 51.403 & 667.969 & 3084 \\
\hline 25 & 0.4 & 61 & 0.5 & 50 & 5 & 20 & 55 & 48.626 & 664.157 & 2966 \\
& & 62 & & & & & & 48.519 & 655.221 & 3008 \\
& & 63 & & & & & & 48.414 & 646.303 & 3050 \\
\hline 25 & 0.4 & 60 & 0.6 & 50 & 5 & 20 & 55 & 49.351 & 661.23 & 2961 \\
& & & 0.7 & & & & & 49.828 & 649.846 & 2990 \\
& & & 0.8 & & & & & 50.209 & 638.798 & 3013 \\
\hline 25 & 0.4 & 60 & 0.5 & 52 & 5 & 20 & 55 & 48.985 & 721.597 & 2939 \\
& & & & 54 & & & & 49.223 & 770.175 & 2953 \\
& & & & 58 & & & & 49.447 & 818.838 & 2967 \\
\hline 25 & 0.4 & 60 & 0.5 & 55 & 5.5 & & 55 & 48.386 & 646.625 & 2903 \\
& & & & & 6.0 & & & 48.054 & 620.324 & 2883 \\
& & & & & 6.5 & & & 47.736 & 594.2 & 2864 \\
\hline 25 & 0.4 & 60 & 0.5 & 50 & 5 & 21 & 55 & 48.733 & 723.11 & 2924 \\
& & & & & & 22 & & 48.733 & 773.112 & 2924 \\
& & & & & & 23 & & 48.733 & 823.112 & 2924 \\
\hline
\end{tabular}


Table 4

Optimal values of production time, profit and optimal ordering quantity (when c is negative)

\begin{tabular}{|c|c|c|c|c|c|c|c|c|c|c|}
\hline $\mathbf{a}$ & c & $\mathbf{k}$ & $\mathbf{h}$ & $\mathbf{R}$ & C & $\mathbf{s}$ & $\mathbf{T}$ & $\mathbf{t}_{\mathbf{1}} *$ & $\mathbf{P}$ & $\mathbf{Q}^{*}$ \\
\hline $\begin{array}{l}25 \\
26 \\
27 \\
28\end{array}$ & -0.3 & 60 & 0.5 & 50 & 5 & 20 & 25 & $\begin{array}{c}13.44 \\
13.344 \\
13.279 \\
13.218 \\
\end{array}$ & $\begin{array}{c}747.276 \\
747.51774 \\
7.748 \\
747.97\end{array}$ & $\begin{array}{c}804.687 \\
800.61 \\
796.739 \\
793.058\end{array}$ \\
\hline 25 & $\begin{array}{l}-0.29 \\
-0.27 \\
-0.25 \\
\end{array}$ & 60 & 0.5 & 50 & 5 & 20 & 25 & $\begin{array}{l}13.423 \\
13.445 \\
13.469 \\
\end{array}$ & $\begin{array}{l}747.218 \\
747.099 \\
746.978\end{array}$ & $\begin{array}{l}805.359 \\
806.732 \\
808.115\end{array}$ \\
\hline 25 & -0.3 & $\begin{array}{l}61 \\
62 \\
63 \\
\end{array}$ & 0.5 & 50 & 5 & 20 & 25 & $\begin{array}{l}13.159 \\
12.913 \\
12.672 \\
\end{array}$ & $\begin{array}{l}743.111 \\
739.049 \\
735.086 \\
\end{array}$ & $\begin{array}{l}802.692 \\
800.576 \\
798.343 \\
\end{array}$ \\
\hline 25 & -0.3 & 60 & $\begin{array}{l}0.6 \\
0.7 \\
0.8 \\
\end{array}$ & 50 & 5 & 20 & 25 & $\begin{array}{c}14.68 \\
15.624 \\
16.353 \\
\end{array}$ & $\begin{array}{c}730.429 \\
715.99 \\
702.605 \\
\end{array}$ & $\begin{array}{c}880.812 \\
937.42 \\
981.162 \\
\end{array}$ \\
\hline 25 & -0.3 & 60 & 0.5 & $\begin{array}{l}52 \\
54 \\
56 \\
\end{array}$ & 5 & 20 & 25 & $\begin{array}{l}14.019 \\
14.616 \\
15.201 \\
\end{array}$ & $\begin{array}{l}787.586 \\
828.481 \\
869.938 \\
\end{array}$ & $\begin{array}{c}891.16 \\
876.945 \\
912.071 \\
\end{array}$ \\
\hline 25 & -0.3 & 60 & 0.5 & 50 & $\begin{array}{l}5.5 \\
6.0 \\
6.5 \\
\end{array}$ & 20 & 25 & $\begin{array}{l}12.678 \\
11.964 \\
11.269 \\
\end{array}$ & $\begin{array}{l}731.624 \\
761.841 \\
702.903 \\
\end{array}$ & $\begin{array}{c}760.67 \\
717.834 \\
676.132 \\
\end{array}$ \\
\hline 25 & -0.3 & 60 & 0.5 & 50 & 5 & $\begin{array}{l}21 \\
22 \\
23\end{array}$ & 25 & $\begin{array}{l}13.411 \\
13.411 \\
13.411\end{array}$ & $\begin{array}{l}797.276 \\
847.276 \\
897.276\end{array}$ & $\begin{array}{l}804.687 \\
804.687 \\
804.687\end{array}$ \\
\hline
\end{tabular}

From Tables $2.3 \& 2.4$, we observe that when the scale parameter, a is increasing, then the time at which production is to be stopped, $t_{1} *$ of $t_{1}$, optimal ordering quantity, $Q^{*}$ of $\mathrm{Q}$, are decreasing. But the profit per unit time, $\mathrm{P}$ is increasing when $\mathrm{c}>0$ and $\mathrm{P}$ the profit per unit time is decreasing when $\mathrm{c}<0$, when other costs and parameters are fixed.

When the shape parameter, $\mathrm{c}$ is increasing positively or negatively then the optimal time at which the production is to be stopped, $\mathrm{t}_{1} *$ of $\mathrm{t}_{1}$ and the optimal ordering quantity, $\mathrm{Q} *$ of $\mathrm{Q}$ are increasing and the profit per unit time, $\mathrm{P}$ is decreasing, when other costs and parameters are fixed.

When holding cost, $\mathrm{h}$ is increasing then the optimal time at which production is to be stopped, $\mathrm{t}_{1} *$ of $\mathrm{t}_{1}$, and the optimal ordering quantities, $\mathrm{Q}^{*}$ of $\mathrm{Q}$ are increasing and the profit per unit time, $\mathrm{P}$ is decreasing, when other costs and parameters are fixed.

When the demand rate, $R$ is increasing then the optimal time at which production is to be stopped $t_{1} *$ of $t_{1}$, and the optimal ordering quantities, $\mathrm{Q}^{*}$ of $\mathrm{Q}$, and the profit per unit time, $\mathrm{P}$ are increasing, when other costs and parameters are fixed.

When cost per unit $\mathrm{C}$, is increasing then the optimal ordering quantities, $\mathrm{Q}^{*}$ of $\mathrm{Q}$, and the profit per unit time, $\mathrm{P}$, the optimal time at which production is to be stopped $t_{1} *$ of $t_{1}$ are decreasing, when other costs and parameters are fixed. When production rate, $\mathrm{k}$ is increasing then the optimal time at which production is to be stopped $t_{1} *$ of $t_{1}$ is decreasing. But the profit per unit time, $P$ and the optimal ordering quantities, $Q^{*}$ of $Q$ are increasing for $\mathrm{c}>0$ and are decreasing for $\mathrm{c}<0$, when other costs and parameters are fixed. 
When the unit selling price, $\mathrm{s}$ is increasing then the optimal time at which the production is to be stopped $t_{1} *$ of $t_{1}$ and the optimal ordering quantity, $Q^{*}$ of $Q$ are remain the same and the profit per unit time, $P$ is increasing, when other costs and parameters a fixed.

\section{CONCLUSIONS}

In this paper we developed and analyzed an inventory model for deteriorating items with the assumptions that the lifetime of the community is random and follows a Generalized Pareto distribution, having constant demand rate with shortages. The total cycle length in this model is divided into our non-over lapping intervals depending on the decrease of stock. The losses due to deterioration, the total backlogged demand, the ordering quantity are also derived with suitable cost consideration. The total profit per unit time is developed and optimized with respect to the time at which production is to be started, time at which shortages occur, the time at which production is to be restated. The optimal ordering quantity, $\mathrm{Q}$ is also obtained for given values of the parameters. The without shortages model is also analyzed as a limiting case. The proposed model is much useful in developing the optimal pricing and ordering policies of an inventory situation in photochemical industries, food processing units, material handling, fruit and vegetable markets.

\section{REFERENCES}

1. Chang, H., Dye, C. (1999) "An EOQ model for deteriorating items with time varying demand and partial backlogging”. J Oper Res Soc 50, 1176-1182.

2. Moncer Hariga (1996) "Optimal EOQ Models for Deteriorating Items with Time-Varying Demand" Journal of the Operational Research Society Volume 47, 1996 - Issue 10, pp.1228-1246.

3. Ali Akbar Shaikh et al., (2019) "Price discount facility in an EOQ model for deteriorating items with stock-dependent demand and partial backlogging” International Transactions In Operational Research, pp. 1365-1395.

4. Zhou, Y., Chen, C., Li, C., Zhong, Y.: (2016) "A synergic economic order quantity model with trade credit, shortages, imperfect quality and inspection errors" Appl. Math. Model. 40, pp. 1012-1028.

5. Shin, M., Lee, H., Ryu, K., Cho, Y., \& Son, Y. J. (2019). A two-phased perishable inventory model for production planning in a food industry. Computers \& Industrial Engineering, 133, 175-185.

6. Janssen, L., Sauer, J., Claus, T., \& Nehls, U. (2018) "Development and simulation analysis of a new perishable inventory model with a closing days constraint under non-stationary stochastic demand" Computers \& Industrial Engineering, 118, 9-22.

7. Saranya, N., \& Lawrence, A. S. (2019). A stochastic inventory system with replacement of perishable items. Opsearch, 56 (2), pp. 563-582.

8. Mandal, D., \& Venkataraman, S. V. (2019) "A dynamic programming model for perishable inventory management” International Journal of Operational Research, 35(2), pp. 147-177.

9. Bhaula, B., Dash, J. K., \& Kumar, M. R. (2019). “An optimal inventory model for perishable items under successive price discounts with permissible delay in payments" Opsearch, 56(1), 261-281.

10. Saha, S., \& Sen, N. (2019). "An inventory model for deteriorating items with time and price dependent demand and shortages under the effect of inflation" International Journal of Mathematics in Operational Research, 14(3), 377-388.

11. Waliv, R. H., \& Umap, H. P. (2019). "Stochastic inventory model with income and price dependent demand" International Journal of Procurement Management, 12(5), pp. 606-620.

12. Liao, J., Huang, K., Chung, K. et al. (2020) Optimal ordering policy in an economic order quantity (EOQ) model for non-instantaneous deteriorating items with defective quality and permissible delay in payments. RACSAM 114, pp. 41

13. Aljazzar, S.M., Jaber, M.Y., Moussawi-Haidar, L.: (2017) Coordination of a three-level supply chain (suppliermanufacturer-retailer) with permissible delay in payments and price discounts. Appl. Math. Model.-48, 289-302.

14. Chakraborty, D., Jana, D.K., Roy, T.K.: (2018) "Two-warehouse partial backlogging inventory model with ramp type demand rate, three-parameter Weibull distribution deterioration under inflation and permissible delay in payments". Computers \& Industrial Engineering.-123, pp. 157-179. 